\title{
Adubação nitrogenada suplementar tardia em soja cultivada em latossolos do Cerrado
}

\author{
lêda de Carvalho Mendes ${ }^{(1)}$, Fábio Bueno dos Reis Junior(1), Mariangela Hungria( ${ }^{(2)}$, \\ Djalma Martinhão Gomes de Sousa ${ }^{(1)}$ e Rubens José Campo(2)
}

\begin{abstract}
(1)Embrapa Cerrados, BR 020, Km 18, CEP 73310-970 Planaltina, DF. E-mail: mendesi@cpac.embrapa.br, fabio@cpac.embrapa.br, dmgsousa@cpac.embrapa.br ${ }^{(2)}$ Embrapa Soja, Rodovia Carlos João Strass, Distrito de Warta, CEP 86001-970 Londrina, PR. E-mail: hungria@cnpso.embrapa.br, rjcampo@cnpso.embrapa.br
\end{abstract}

\begin{abstract}
Resumo - O objetivo deste trabalho foi avaliar se a adubação nitrogenada, nos estádios de pré-florescimento (R1) e início do enchimento de grãos (R5), interfere na produtividade e na nodulação da soja. O estudo foi realizado por sete anos, em Latossolo Vermelho-Amarelo argiloso e, por quatro anos, em Latossolo Vermelho argiloso, ambos com populações estabelecidas de Bradyrhizobium. Foram conduzidos 15 ensaios, em plantio direto ou convencional, com os seguintes tratamentos: inoculação-padrão (IP) com B. japonicum; IP + $200 \mathrm{~kg} \mathrm{ha}^{-1} \mathrm{de} \mathrm{N}$ (uréia) parcelados em 50\% na semeadura e $50 \%$ em R1; IP $+50 \mathrm{~kg} \mathrm{ha}^{-1}$ de N (nitrato de amônio) em R1; IP + $50 \mathrm{~kg} \mathrm{ha}^{-1}$ de N (sulfato de amônio) em R1; IP + $50 \mathrm{~kg} \mathrm{ha}^{-1}$ de N (nitrato de amônio) em R5; e IP + $50 \mathrm{~kg} \mathrm{ha}^{-1}$ de $\mathrm{N}$ (sulfato de amônio) em R5. A aplicação de $200 \mathrm{~kg} \mathrm{ha}^{-1}$ de N prejudicou a nodulação. Em apenas dois ensaios, houve resposta à aplicação de $\mathrm{N}$, no entanto, sem retorno econômico ao produtor. A adubação nitrogenada tardia, no cultivo da soja com inoculação, em latossolos do Cerrado, não se justifica economicamente, em nenhum dos sistemas de cultivo avaliados, independentemente da fonte de $\mathrm{N}$ utilizada.
\end{abstract}

Termos para indexação: Bradyrhizobium japonicum, Glycine max, enchimento de grãos, fertilizantes nitrogenados, fixação biológica de nitrogênio, pré-florescimento.

\section{Late supplemental nitrogen fertilization on soybean cropped in Cerrado Oxisols}

\begin{abstract}
The objective of this work was to evaluate the effects of nitrogen fertilization at the pre-flowering (R1) and seed filling (R5) stages, on the nodulation and yield of soybean grown in Cerrado Oxisols. The study was performed for seven years in a clayey Typic Haplustox, and for four years in a clayey Rhodic Haplustox, both with established populations of Bradyrhizobium. Fifteen experiments were carried out under conventional and no tillage management systems and the treatments were: standard inoculation (SI) with B. japonicum; $\mathrm{SI}+200 \mathrm{~kg} \mathrm{ha}^{-1} \mathrm{~N}$ (urea), split-applied $50 \%$ at sowing and $50 \%$ at the R1 stage; $\mathrm{SI}+50 \mathrm{~kg} \mathrm{ha}^{-1} \mathrm{~N}$ (ammonium nitrate) in R1; $\mathrm{SI}+50 \mathrm{~kg} \mathrm{ha}^{-1} \mathrm{~N}$ (ammonium sulfate) in R1; $\mathrm{SI}+50 \mathrm{~kg} \mathrm{ha}^{-1} \mathrm{~N}$ (ammonium nitrate) in R5; and $\mathrm{SI}+50 \mathrm{~kg} \mathrm{ha}^{-1} \mathrm{~N}$ (ammonium sulfate) in R5. The application of $200 \mathrm{~kg} \mathrm{ha}^{-1} \mathrm{~N}$ harmed nodulation. In only two experiments, the yield responses to late season $\mathrm{N}$ applications were significant, with no net economical benefits for the producer. Late nitrogen fertilization on inoculated soybean, grown under Brazilian Cerrados Oxisols, has no economical advantages in any of the management systems evaluated, regardless of the $\mathrm{N}$ source applied.
\end{abstract}

Index terms: Bradyrhizobium japonicum, Glycine max, seed filling, nitrogen fertilizers, biological nitrogen fixation, pre-flowering.

\section{Introdução}

Os programas de melhoramento da cultura da soja, em conjunto com a seleção de estirpes de Bradyrhizobium adaptadas às condições do Cerrado, capazes de substituir totalmente o uso de adubos nitrogenados, foram, sem dúvida, um dos fatores que mais contribuíram para a expansão da cultura nessa região (Peres \& Vidor, 1980; Vargas \& Suhet, 1980; Peres et al., 1993). Além disso, um programa bem sucedido de seleção de estirpes de rizóbio, no Brasil, tem permitido o lançamento de novas estirpes capazes de aumentar o rendimento da cultura da soja, mesmo em áreas com populações estabelecidas dessa bactéria (Hungria et al., 2005, 2006b). Ao contrário, em países como China e Estados Unidos, a reinoculação, ou seja, a inoculação em sementes a serem semeadas em áreas cultivadas anteriormente com soja com inoculação, não apresenta resultados satisfatórios 
no rendimento de grãos, tendo sido necessário, em alguns casos, fazer a complementação com adubo nitrogenado (Thies et al., 1991, 1995; Wesley et al., 1998; Gan et al., 2002, 2003).

No Brasil, as taxas de fixação biológica do nitrogênio (FBN), para a cultura da soja, variam entre 109 e $250 \mathrm{~kg} \mathrm{ha}^{-1}$ de N, o que representa de 70 a $85 \%$ do N total acumulado pelas plantas (Boddey et al., 1990; Hungria et al., 2006a). Contudo, uma análise de vários experimentos, conduzidos principalmente nos Estados Unidos e Austrália, mostrou que o $\mathrm{N}$ derivado da fixação biológica na soja, nesses países, tem decrescido de 65 para $54 \%$, provavelmente em razão do aumento da utilização de fertilizantes nitrogenados (van Kessel \& Hartley, 2000).

Desde o início da expansão do cultivo da soja, em áreas de primeiro cultivo no Cerrado, na década de 1970, houve dúvidas, por parte dos agricultores, de que somente a inoculação fosse suficiente para suprir todo o $\mathrm{N}$ necessário para se alcançar boas produtividades. Várias pesquisas realizadas na década de 80 (Vargas \& Suhet, 1980; Vargas et al., 1982) demonstraram que, utilizando-se inoculantes de boa qualidade, com estirpes adaptadas às condições de Cerrado, a prática da adubação nitrogenada na cultura da soja era totalmente desnecessária. Mesmo em solos com grande quantidade de resíduos vegetais $\left(26 \mathrm{Mg} \mathrm{ha}^{-1}\right)$, não é observada resposta da soja à aplicação de fertilizantes nitrogenados na semeadura, para a superação de possíveis problemas relacionados à imobilização do $\mathrm{N}$ mineral do solo ou à competição inicial com ervas daninhas (Vargas et al., 1982). Mais recentemente, Hungria et al. (1997) e Mendes et al. (2003) confirmaram que não há necessidade da utilização de doses de "arranque" com adubo nitrogenado na semeadura, tanto em áreas de plantio direto, quanto de plantio convencional da soja.

Entretanto, fatores como o avanço do plantio direto na Região do Cerrado, o lançamento de cultivares com teto elevado de produtividade e resultados de pesquisa, obtidos nos Estados Unidos (Wesley et al., 1998; Lamond \& Wesley, 2001), com resposta da soja à aplicação tardia de $\mathrm{N}$, no pré-florescimento e no início do enchimento de grãos, voltaram a gerar dúvidas sobre a necessidade de se adubar a soja brasileira com fertilizantes nitrogenados. Essas informações precisam ser avaliadas de forma sistematizada pela pesquisa, pois podem desestimular o agricultor quanto à necessidade da prática de reinoculação em soja, o que poderia acarretar prejuízos para a FBN.
O objetivo deste trabalho foi avaliar se a adubação nitrogenada tardia interfere na produtividade e na nodulação da soja com inoculação de Bradyrhizobium japonicum, cultivada em latossolos de Cerrado, com populações estabelecidas dessa bactéria.

\section{Material e Métodos}

Foram conduzidos na Embrapa Cerrados, em Planaltina, DF, 15 ensaios entre as safras de 2000/2001 a 2005/2006, em latossolos com populações estabelecidas de Bradyrhizobium superiores a $10^{4}$ células g-1 de solo (contagens realizadas em plantas pela técnica do número mais provável).

Dos 15 experimentos, 12 foram conduzidos em Latossolo Vermelho-Amarelo (LVA) argiloso: seis experimentos sob o sistema de plantio direto (PD) e seis sob plantio convencional (PC). As áreas de PD e $\mathrm{PC}$ eram adjacentes e vinham sendo cultivadas sob esses dois sistemas desde 1993. Essas áreas foram desmatadas em 1978, cultivadas no sistema convencional por três anos, e então permaneceram em pousio até 1993, quando passaram a ser cultivadas nos sistemas de PD e PC. Em ambas as áreas, a soja foi cultivada após o milho. Os outros três experimentos foram conduzidos em Latossolo Vermelho distroférrico (LVd), de textura muito argilosa, desmatado em 1980 e cultivado, em seguida, com soja e milho no sistema de PC. Os resultados da análise química desses solos estão apresentados na Tabela 1.

O delineamento dos 15 experimentos foi o de blocos ao acaso, com quatro repetições. Os tratamentos avaliados foram: inoculação-padrão (IP) com as estirpes SEMIA 5079 (CPAC-15) e SEMIA 5080 (CPAC-7) à dose de $500 \mathrm{~g}$ de inoculante turfoso por $50 \mathrm{~kg}$ de sementes ( $10^{6}$ células por semente); IP $+200 \mathrm{~kg} \mathrm{ha}^{-1} \mathrm{de}$ $\mathrm{N}$, na forma de uréia, divididos em uma aplicação de $100 \mathrm{~kg} \mathrm{ha}^{-1} \mathrm{de} \mathrm{N}$ na semeadura e outra de $100 \mathrm{~kg} \mathrm{ha}^{-1}$ no estágio R1 (início do florescimento); $\mathrm{IP}+50 \mathrm{kgha}^{-1} \mathrm{de} \mathrm{N}$, na forma de nitrato de amônio, em R1; IP $+50 \mathrm{~kg} \mathrm{ha}^{-1} \mathrm{de}$ $\mathrm{N}$, na forma de sulfato de amônio, em R1; IP $+50 \mathrm{~kg} \mathrm{ha}^{-1}$ de $\mathrm{N}$, na forma de nitrato de amônio, em R5 (enchimento de grãos); e IP $+50 \mathrm{~kg} \mathrm{ha}^{-1}$ de N, na forma de sulfato de amônio, em R5. A área das parcelas foi de $8 \times 4 \mathrm{~m}$, nos experimentos conduzidos em LVA, e de $6 \times 4 \mathrm{~m}$, nos experimentos conduzidos em LVd.

Em cada experimento, a correção e adubação com $\mathrm{P}$, $\mathrm{K}, \mathrm{S}$ e micronutrientes foram realizadas de acordo com os resultados da análise do solo (Tabela 1), expectativa de produção da soja e histórico da área (Sousa \& 
Lobato, 2002). Nas áreas localizadas no LVA, a cultivar EMGOPA 316 (ciclo curto, 116 dias) foi utilizada, com exceção dos anos agrícolas 2004/2005 e 2005/2006, em que foi utilizada a cultivar EMGOPA 313 (ciclo longo, 138 dias). Nos experimentos conduzidos em LVd, foi utilizada a cultivar Celeste (ciclo longo, 136 dias).

Em todos os experimentos, a densidade de plantio foi de 17 sementes por metro, com espaçamento entre linhas de $45 \mathrm{~cm}$. Avaliaram-se a nodulação das plantas (massa de matéria seca de nódulos) e a produtividade de grãos.

As amostragens para avaliação da nodulação das plantas foram feitas na fase de florescimento pleno (R2), com a coleta de seis plantas por parcela. Neste trabalho, o efeito da aplicação de $\mathrm{N}$ em R5, na massa de matéria seca de nódulos, não foi avaliado, em razão do elevado número de nódulos senescentes presentes nesse estádio de desenvolvimento da soja, que dificultaria a avaliação precisa da nodulação. Os nódulos foram destacados, lavados e secados em estufa com ventilação forçada de ar a $65^{\circ} \mathrm{C}$, para determinação da massa de matéria seca nodular.A produção de grãos foi calculada com base na colheita de uma área útil de $12,6 \mathrm{~m}^{2}$ nos experimentos do LVA, e de $10 \mathrm{~m}^{2}$ nos experimentos do LVd, tendo-se corrigido a umidade para $13 \%$.

As análises de variância para cada experimento foram efetuadas utilizando-se o SAS (SAS Institute, 2000), e as diferenças estatísticas foram determinadas pelo teste de Duncan, a 5\% de probabilidade. Para cada uma das três áreas (LVA em plantio direto ou convencional e LVd), foi feita também a análise conjunta dos dados que englobou os anos de cultivo.

\section{Resultados e Discussão}

Nas três áreas, a nodulação da soja foi abundante (Tabelas 2 e 3). De maneira geral, a aplicação de $200 \mathrm{~kg} \mathrm{ha}^{-1}$ de N influenciou negativamente a nodulação, em todas elas. Essa redução na massa de matéria seca de

Tabela 1. Propriedades químicas do Latossolo Vermelho-Amarelo (LVA) e do Latossolo Vermelho (LVd), em plantio direto (PD) e convencional (PC), à época de implantação dos experimentos: 1999 e 2001, respectivamente, para os experimentos conduzidos no LVA e no LVd.

\begin{tabular}{|c|c|c|c|c|c|c|c|}
\hline Solo & Sistema de manejo do solo & $\begin{array}{l}\text { Profundidade } \\
(\mathrm{cm})\end{array}$ & $\mathrm{pH}\left(\mathrm{H}_{2} \mathrm{O}\right)$ & $\begin{array}{c}\text { CTC } \\
\left(\mathrm{cmol}_{\mathrm{c}} \mathrm{dm}^{3}\right)\end{array}$ & $\begin{array}{c}\mathrm{V} \\
(\%)\end{array}$ & $\mathrm{P}$ & $\left(\mathrm{mg} \mathrm{dm}^{3}\right)^{\mathrm{K}}$ \\
\hline \multirow[t]{4}{*}{ LVA } & $\mathrm{PD}$ & 05 & 5,9 & 8,7 & 48 & 22 & 238 \\
\hline & & 520 & 5,6 & 7,8 & 33 & 5 & 58 \\
\hline & $\mathrm{PC}$ & 05 & 5,7 & 7,8 & 43 & 8 & 90 \\
\hline & & 520 & 5,9 & 7,4 & 42 & 6 & 35 \\
\hline LVd & $\mathrm{PC}$ & 020 & 5,4 & 9,8 & 35 & 17 & 135 \\
\hline
\end{tabular}

Tabela 2. Massa de matéria seca de nódulos (mg por planta), em resposta à reinoculação e à aplicação suplementar, tardia, de diferentes fertilizantes nitrogenados, em Latossolo Vermelho-Amarelo argiloso, cultivado sob plantio convencional e direto $^{(1)}$.

\begin{tabular}{|c|c|c|c|c|c|c|c|}
\hline \multirow{2}{*}{ Tratamento $^{(2)}$} & \multicolumn{6}{|c|}{ Safra } & \multirow[t]{2}{*}{ Média } \\
\hline & $2000 / 2001$ & $2001 / 2002$ & $2002 / 2003$ & $2003 / 2004$ & $2004 / 2005$ & $2005 / 2006$ & \\
\hline & \multicolumn{7}{|c|}{ Plantio convencional } \\
\hline Inoculação padrão (IP) & 225,3 & $243,0 \mathrm{a}$ & $252,3 \mathrm{a}$ & $199,0 \mathrm{a}$ & 495,7 & 214,9 & $270,6 \mathrm{a}$ \\
\hline $\mathrm{IP}+50 \mathrm{~kg}$ ha ${ }^{1}$ de $\mathrm{N}$ nitrato de amônio $\mathrm{R} 1$ & 184,9 & $216,5 \mathrm{a}$ & $245,9 \mathrm{a}$ & $146,5 b$ & 464,5 & 250,6 & $253,4 \mathrm{ab}$ \\
\hline $\mathrm{IP}+50 \mathrm{~kg}$ ha ${ }^{1}$ de $\mathrm{N}$ sulfato de amônio R1 & 203,8 & $168,8 \mathrm{a}$ & $228,5 \mathrm{a}$ & $139,8 b$ & 423,9 & 225,6 & $230,6 b$ \\
\hline $\mathrm{IP}+50 \mathrm{~kg}$ ha ${ }^{1}$ de $\mathrm{N}$ nitrato de amônio R5 & 234,6 & $189,0 \mathrm{a}$ & $224,6 a$ & $190,5 \mathrm{a}$ & 517,2 & 230,9 & $264,5 \mathrm{ab}$ \\
\hline $\mathrm{IP}+50 \mathrm{~kg}$ ha ${ }^{1}$ de $\mathrm{N}$ sulfato de amônio R5 & 244,5 & $191,5 \mathrm{a}$ & $243,3 a$ & $209,7 \mathrm{a}$ & 525,4 & 233,5 & $277,5 \mathrm{a}$ \\
\hline $\mathrm{IP}+200 \mathrm{~kg}$ ha ${ }^{1}$ de $\mathrm{N}$ uréia & 170,8 & $103,7 \mathrm{~b}$ & $114,7 \mathrm{~b}$ & $83,7 \mathrm{c}$ & 328,4 & 215,2 & $169,4 \mathrm{c}$ \\
\hline \multirow[t]{2}{*}{$\mathrm{CV}(\%)$} & 24,5 & 24,3 & 16,0 & 18,7 & 19,8 & 29,8 & \\
\hline & \multicolumn{7}{|c|}{ Plantio direto } \\
\hline Inoculação padrão (IP) & 329,0 & $435,9 \mathrm{a}$ & $337,1 \mathrm{a}$ & $246,3 \mathrm{a}$ & 430,0 & $328,0 \mathrm{a}$ & $351,2 \mathrm{a}$ \\
\hline $\mathrm{IP}+50 \mathrm{~kg}$ ha ${ }^{1}$ de $\mathrm{N}$ nitrato de amônio $\mathrm{R} 1$ & 312,5 & $409,9 \mathrm{a}$ & $275,1 \mathrm{a}$ & $198,5 \mathrm{a}$ & 423,6 & $346,9 \mathrm{a}$ & $327,8 \mathrm{a}$ \\
\hline $\mathrm{IP}+50 \mathrm{~kg}$ ha ${ }^{1}$ de $\mathrm{N}$ sulfato de amônio R1 & 284,2 & $400,8 \mathrm{a}$ & $334,0 \mathrm{a}$ & $199,5 \mathrm{a}$ & 462,1 & $390,7 \mathrm{a}$ & $345,2 \mathrm{a}$ \\
\hline $\mathrm{IP}+50 \mathrm{~kg}$ ha ${ }^{1}$ de $\mathrm{N}$ nitrato de amônio R5 & 349,5 & $423,6 a$ & $345,5 \mathrm{a}$ & $234,2 \mathrm{a}$ & 450,0 & $330,0 \mathrm{a}$ & $356,2 \mathrm{a}$ \\
\hline $\mathrm{IP}+50 \mathrm{~kg}$ ha ${ }^{1}$ de $\mathrm{N}$ sulfato de amônio R5 & 382,7 & $448,1 \mathrm{a}$ & $313,6 a$ & $242,9 \mathrm{a}$ & 351,0 & $339,0 \mathrm{a}$ & $346,2 \mathrm{a}$ \\
\hline IP $+200 \mathrm{~kg}$ ha ${ }^{1}$ de $\mathrm{N}$ uréia & 208,6 & $238,7 \mathrm{~b}$ & $175,6 \mathrm{~b}$ & $103,5 b$ & 290,0 & $234,9 \mathrm{~b}$ & $208,5 b$ \\
\hline $\mathrm{CV}(\%)$ & 23,0 & 15,4 & 15,0 & 27,1 & 22,8 & 13,5 & \\
\hline
\end{tabular}


nódulos por planta foi, em média, de 21, 37 e $41 \%$, nas áreas sob PC (LVd e LVA) e PD (LVA), respectivamente. Além do tratamento com $200 \mathrm{~kg} \mathrm{ha}^{-1}$ de $\mathrm{N}$, apenas os tratamentos com aplicação de $50 \mathrm{~kg} \mathrm{ha}^{-1} \mathrm{de} \mathrm{N}$, no início do florescimento, nas formas de nitrato de amônio ou sulfato de amônio, reduziram a massa de matéria seca de nódulos, na safra 2003/2004, em LVA sob plantio convencional (Tabela 2). Nessa mesma área, a análise conjunta dos experimentos conduzidos entre as safras 2000/2001 e 2005/2006, também evidenciou o efeito do tratamento com aplicação de $50 \mathrm{~kg} \mathrm{ha}^{-1} \mathrm{de} \mathrm{N}$, como sulfato de amônio, no início do florescimento, com prejuízo para a nodulação.

Em suas formas minerais, $\mathrm{NO}_{3}^{-}{ }^{-} \mathrm{NH}_{4}^{+}, \mathrm{o} N$ presente no solo afeta não só a fixação biológica, mas também a nodulação das plantas, por inibir a formação ou causar senescência dos nódulos já formados (Bottomley \& Myrold, 2007). Hungria et al. (2006b) observaram que a aplicação, no plantio, de uma dose de "arranque" de $30 \mathrm{~kg} \mathrm{ha}^{-1}$ de $\mathrm{N}$ promoveu decréscimo no peso de nódulos. Esses mesmos autores relatam que a aplicação de $50 \mathrm{~kg} \mathrm{ha}^{-1}$ de Nnos estágios R2 e R4 promoveu redução na nodulação secundária, o que resultou na diminuição da quantidade de nitrogênio fixado biologicamente, e afetou negativamente o rendimento de grãos.

Comparando-se as médias da massa de matéria seca de nódulos das plantas, dos experimentos conduzidos em LVA, sob diferentes sistemas de manejo do solo, observa-se que a soja sob PD apresentou massa nodular $32 \%$ maior do que a soja sob PC (Tabela 2). Resultados semelhantes foram observados por Hungria (2000), em estudos conduzidos no Paraná. Aumentos no número de células de Rhizobium e Bradyrhizobium e o acúmulo de flavonóides indutores dos genes de nodulação, em áreas sob PD, em comparação a áreas sob PC, também foram reportados por Ferreira et al. (2000) e Hungria, (2000). Ao permitir maior acúmulo de matéria orgânica e melhorar a agregação do solo, com aumento da capacidade de retenção de água e diminuição das oscilações térmicas, o sistema de plantio direto favorece os microrganismos (Hungria, 2000), além de criar um ambiente mais propício para o crescimento radicular e, conseqüentemente, a ocorrência de maior número de sítios de infecção e nodulação para os bradirrizóbios. Recentemente, também no Paraná, Pereira et al. (2007) não verificaram diferenças na massa nodular entre o PD e o PC. Entretanto, em PD, a relação N na parte aérea e massa nodular foi maior, o que indica que nesse sistema de manejo os nódulos foram mais eficientes.

$\mathrm{Na}$ Tabela 4, pode-se observar que, em LVA sob plantio convencional, não foram detectadas diferenças estatísticas no rendimento de grãos entre os tratamentos, exceto na safra 2002/2003, quando houve resposta significativa à adubação com $200 \mathrm{~kg} \mathrm{ha}^{-1} \mathrm{de} \mathrm{N}$, na forma de uréia, parcelados entre semeadura e R1. Na análise conjunta dos seis experimentos conduzidos nessa área, os rendimentos de grãos obtidos nos tratamentos com adubação nitrogenada, com exceção do tratamento $50 \mathrm{~kg} \mathrm{ha}^{-1} \mathrm{de} \mathrm{N}$, na forma de nitrato de amônio, aplicado em R5, foram superiores ao do tratamento apenas com inoculação. Os ganhos de produtividade com $\mathrm{N}$ foram, em média, de $154 \mathrm{~kg} \mathrm{ha}^{-1}$ de grãos.

Na Tabela 4, observa-se também que, em LVA sob plantio direto, apenas na safra 2000/2001 houve resposta significativa à adubação com $50 \mathrm{~kg} \mathrm{ha}^{-1} \mathrm{de} \mathrm{N}$ na forma de sulfato de amônio, na fase R5. Nas demais safras, não houve diferença entre os tratamentos. Na análise conjunta dos seis experimentos, os tratamentos com $50 \mathrm{~kg} \mathrm{ha}^{-1} \mathrm{de}$ $\mathrm{N}$, na forma de sulfato de amônio, aplicados em R5, e $200 \mathrm{~kg} \mathrm{ha}^{-1}$ de $\mathrm{N}$, na forma de uréia, apresentaram rendimentos superiores aos do tratamento apenas com

Tabela 3. Massa de matéria seca de nódulos (mg por planta), em resposta à reinoculação e à aplicação suplementar, tardia, de diferentes fertilizantes nitrogenados em Latossolo Vermelho argiloso, cultivado sob plantio convencional ${ }^{(1)}$.

\begin{tabular}{|c|c|c|c|c|}
\hline \multirow[t]{2}{*}{ Tratamento $^{(2)}$} & \multicolumn{3}{|c|}{ Safra } & \multirow[t]{2}{*}{ Média } \\
\hline & $2001 / 2002$ & $2002 / 2003$ & $2003 / 2004$ & \\
\hline Controle (IP) & 246,0 & 203,2 & 169,7 & $189,8 \mathrm{ab}$ \\
\hline $\mathrm{IP}+50 \mathrm{~kg}$ ha ${ }^{1}$ de $\mathrm{N}$ nitrato de amônio $\mathrm{R} 1$ & 206,1 & 191,8 & 143,9 & $180,6 \mathrm{ab}$ \\
\hline $\mathrm{IP}+50 \mathrm{~kg}$ ha ${ }^{1}$ de $\mathrm{N}$ sulfato de amônio R1 & 192,8 & 197,6 & 148,7 & $179,7 \mathrm{ab}$ \\
\hline $\mathrm{IP}+50 \mathrm{~kg}$ ha ${ }^{1}$ de $\mathrm{N}$ nitrato de amônio R5 & 211,9 & 224,5 & 160,2 & $198,9 \mathrm{a}$ \\
\hline IP $+50 \mathrm{~kg}$ ha ${ }^{1}$ de $\mathrm{N}$ sulfato de amônio R5 & 206,0 & 167,0 & 162,5 & $178,5 \mathrm{ab}$ \\
\hline $\mathrm{IP}+200 \mathrm{~kg}$ ha ${ }^{1}$ de $\mathrm{N}$ uréia & 194,1 & 129,9 & 125,7 & $149,9 \mathrm{~b}$ \\
\hline $\mathrm{CV}(\%)$ & 17,9 & 26,5 & 32,6 & \\
\hline
\end{tabular}

${ }^{(1)}$ Médias seguidas por letras iguais, na coluna, não diferem entre si pelo teste de Duncan, a 5\% de probabilidade. ${ }^{(2)}$ IP: inoculação-padrão com as estirpes SEMIA 5079 e SEMIA 5080 ( $10^{6}$ células por semente); o tratamento com $200 \mathrm{~kg} \mathrm{ha}^{-1} \mathrm{de} \mathrm{N}$ teve aplicação dividida em $100 \mathrm{~kg}$ ha ${ }^{-1}$ na semeadura e $100 \mathrm{~kg}^{-1}$ no estágio R1. 
inoculação, com aumento médio de $176 \mathrm{~kg} \mathrm{ha}^{-1} \mathrm{de}$ grãos.

Em nenhum dos três experimentos conduzidos em LVd houve diferenças entre os tratamentos (Tabela 5). Entretanto, na análise conjunta, o tratamento com $200 \mathrm{~kg} \mathrm{ha}^{-1}$ de $\mathrm{N}$, na forma de uréia, e os tratamentos adubados com nitrato de amônio e sulfato de amônio em R5 apresentaram rendimento de grãos superior ao obtido apenas com a inoculação. Esses ganhos de produtividade foram, em média, de $216 \mathrm{~kg}$ de grãos ha ${ }^{-1}$.

Ao se analisar a média dos rendimentos de grãos da soja, em cada uma das três áreas, observa-se que a aplicação de nitrato de amônio e sulfato de amônio, nas fases de pré-florescimento e enchimento de grãos, promoveu aumentos no rendimento da cultura, que variaram de 1 a 4,3 sacas ha-1 de soja (Tabelas 4 e 5).
No entanto, mesmo um ganho de 4 sacas ha ${ }^{-1}$ de soja não resultaria em lucro para os produtores, ao se considerarem os preços de US\$119 para $50 \mathrm{~kg}$ de sulfato de amônio e de US\$23 para a saca de soja - cotados no Distrito Federal, em novembro de 2007 -, sem inclusão do custo do transporte do adubo e de sua aplicação. Hungria et al. (2006b), em experimentos conduzidos sob PD e PC, em Londrina e Ponta Grossa, PR, verificaram que a aplicação de $50 \mathrm{~kg} \mathrm{ha}^{-1}$ de $\mathrm{N}$ na forma de uréia, tanto no estágio R2 quanto no R4, não promoveu ganhos de produtividade na soja.

Ainda que não justifiquem economicamente a aplicação suplementar de $\mathrm{N}$ na soja, os aumentos nos rendimentos de grãos da soja, nas condições do Cerrado, apontam para a necessidade permanente de aprimoramento dos

Tabela 4. Rendimento de grãos de soja $\left(\mathrm{kg} \mathrm{ha}^{-1}\right)$, em resposta à reinoculação e à aplicação suplementar, tardia, de diferentes fertilizantes nitrogenados em Latossolo Vermelho-Amarelo argiloso, cultivado sob plantio convencional e direto ${ }^{(1)}$.

\begin{tabular}{|c|c|c|c|c|c|c|c|}
\hline \multirow[t]{2}{*}{ Tratamento $^{(2)}$} & \multicolumn{6}{|c|}{ Safra } & \multirow[t]{2}{*}{ Média } \\
\hline & $2000 / 2001$ & $2001 / 2002$ & $2002 / 2003$ & $2003 / 2004$ & $2004 / 2005$ & $2005 / 2006$ & \\
\hline & \multicolumn{7}{|c|}{ Plantio convencional } \\
\hline Inoculação padrão (IP) & 3.282 & 2.868 & $3.245 b$ & 3.482 & 2.971 & 3.797 & $3.280 \mathrm{c}$ \\
\hline $\mathrm{IP}+50 \mathrm{~kg} \mathrm{ha}^{-1}$ de $\mathrm{N}$ nitrato de amônio R1 & 3.520 & 2.999 & $3.236 \mathrm{~b}$ & 3.640 & 3.185 & 4.130 & $3.433 \mathrm{a}$ \\
\hline $\mathrm{IP}+50 \mathrm{~kg} \mathrm{ha}^{-1}$ de $\mathrm{N}$ sulfato de amônio R1 & 3.431 & 3.042 & $3.214 \mathrm{~b}$ & 3.614 & 3.147 & 3.881 & $3.407 \mathrm{ab}$ \\
\hline $\mathrm{IP}+50 \mathrm{~kg} \mathrm{ha}^{-1}$ de $\mathrm{N}$ nitrato de amônio R5 & 3.398 & 2.956 & $3.330 \mathrm{ab}$ & 3.670 & 2.759 & 3.921 & $3.339 \mathrm{abc}$ \\
\hline $\mathrm{IP}+50 \mathrm{~kg} \mathrm{ha}^{-1}$ de $\mathrm{N}$ sulfato de amônio R5 & 3.405 & 3.186 & $3.318 \mathrm{ab}$ & 3.711 & 3.213 & 3.844 & $3.447 \mathrm{a}$ \\
\hline IP $+200 \mathrm{~kg} \mathrm{ha}^{-1}$ de N uréia & 3.491 & 3.116 & $3.442 \mathrm{a}$ & 3.660 & 3.052 & 3.885 & $3.441 \mathrm{a}$ \\
\hline \multirow[t]{2}{*}{ CV $(\%)$} & 7,0 & 7,1 & 2,6 & 7,3 & 9,6 & 7,3 & \\
\hline & \multicolumn{7}{|c|}{ Plantio direto } \\
\hline Inoculação padrão (IP) & $3.466 b$ & 2.827 & 2.871 & 3.187 & 2.976 & 3.562 & $3.148 b$ \\
\hline $\mathrm{IP}+50 \mathrm{~kg} \mathrm{ha}^{-1}$ de $\mathrm{N}$ nitrato de amônio R1 & $3.607 \mathrm{ab}$ & 2.772 & 2.889 & 3.009 & 3.361 & 3.833 & $3.250 \mathrm{ab}$ \\
\hline $\mathrm{IP}+50 \mathrm{~kg} \mathrm{ha}^{-1}$ de $\mathrm{N}$ sulfato de amônio R1 & $3.571 \mathrm{ab}$ & 2.826 & 2.952 & 3.210 & 3.381 & 3.682 & $3.260 \mathrm{ab}$ \\
\hline $\mathrm{IP}+50 \mathrm{~kg} \mathrm{ha}^{-1}$ de $\mathrm{N}$ nitrato de amônio R5 & $3.796 \mathrm{ab}$ & 2.878 & 2.787 & 3.394 & 3.051 & 3.711 & $3.269 \mathrm{ab}$ \\
\hline $\mathrm{IP}+50 \mathrm{~kg} \mathrm{ha}^{-1}$ de $\mathrm{N}$ sulfato de amônio R5 & $3.872 \mathrm{a}$ & 2.919 & 2.818 & 3.247 & 3.279 & 3.820 & $3.326 \mathrm{a}$ \\
\hline $\mathrm{IP}+200 \mathrm{~kg} \mathrm{ha}^{-1}$ de N uréia & $3.764 \mathrm{ab}$ & 3.017 & 2.791 & 3.075 & 3.261 & 3.838 & $3.323 \mathrm{a}$ \\
\hline
\end{tabular}

${ }^{(1)}$ Médias seguidas por letras iguais, na coluna, não diferem entre si pelo teste de Duncan, a 5\% de probabilidade. ${ }^{(2)}$ IP: inoculação-padrão com as estirpes SEMIA 5079 e SEMIA 5080 ( $10^{6}$ células por semente); o tratamento com $200 \mathrm{~kg} \mathrm{ha}^{-1} \mathrm{de} \mathrm{N}$ teve aplicação dividida em $100 \mathrm{~kg}$ ha ${ }^{-1}$ na semeadura e $100 \mathrm{~kg}^{-1}$ no estágio R1.

Tabela 5. Rendimento de grãos de soja $\left(\mathrm{kg} \mathrm{ha}^{-1}\right)$, em resposta à reinoculação e à aplicação suplementar, tardia, de diferentes fertilizantes nitrogenados, em Latossolo Vermelho argiloso, cultivado sob plantio convencional ${ }^{(1)}$.

\begin{tabular}{lccc}
\hline Tratamento $^{(2)}$ & & Safra & Média \\
\cline { 2 - 3 } & $2001 / 2002$ & $2002 / 2003$ & $2003 / 2004$ \\
\hline Inoculação padrão (IP) & 3.701 & 4.159 & 3.711 \\
IP + 50 kg ha ${ }^{-1}$ de N nitrato de amônio R1 & 3.697 & 4.332 & 3.892 \\
IP + 50 kg ha de N sulfato de amônio R1 & 3.844 & 4.347 & $3.857 \mathrm{~b}$ \\
IP + 50 kg ha de N nitrato de amônio R5 & 3.947 & 4.382 & $3.973 \mathrm{ab}$ \\
IP + 50 kg ha ${ }^{-1}$ de N sulfato de amônio R5 & 3.912 & 4.382 & 3.764 \\
IP + $200 \mathrm{~kg} \mathrm{ha}^{-1}$ de N uréia & 3.923 & 4.371 & 3.934 \\
CV $(\%)$ & 4,8 & 6,6 & $4.031 \mathrm{a}$ \\
\hline
\end{tabular}

${ }^{(1)}$ Médias seguidas por letras iguais, não diferem entre si pelo teste de Duncan, a 5\% de probabilidade. ${ }^{(2)}$ IP: inoculação-padrão com as estirpes SEMIA 5079 e SEMIA 5080 ( $10^{6}$ células por semente); o tratamento com $200 \mathrm{~kg} \mathrm{ha}^{-1}$ de $\mathrm{N}$ teve aplicação dividida em $100 \mathrm{~kg}^{-1} \mathrm{na}^{-2} \mathrm{meadura}$ e $100 \mathrm{~kg}$ ha-1 no estágio R1. 
estudos em FBN, para que esse processo possa continuar suprindo as crescentes necessidades da cultura da soja em N, em conseqüência do aumento nos tetos de produtividade.

$\mathrm{Na}$ literatura internacional, estudos de campo sobre a adubação nitrogenada tardia da soja evidenciam tanto a ocorrência (Wesley et al., 1998; Gan et al., 2003) quanto a ausência de ganhos de produtividade (Papacosta \& Veresoglou, 1989; Wood et al., 1993; Koutroubas et al., 1998). Entretanto, os resultados obtidos em outros países não podem ser extrapolados para as condições brasileiras, tendo-se em vista que as interações entre o tipo de solo e os genótipos do macro e microssimbionte variam de acordo com cada local. Por exemplo: diferentemente dos resultados reportados neste trabalho, nos experimentos conduzidos por Wesley et al. (1998), no Kansas, EUA, o aumento médio de produtividade foi de $470 \mathrm{~kg}$ de grãos, com a aplicação tardia (estádio R3) de apenas $20 \mathrm{~kg} \mathrm{ha}^{-1} \mathrm{de} \mathrm{N}$. De acordo com esses autores, as respostas à adubação suplementar tardia só ocorreram em áreas em que o potencial de produtividade da soja era elevado (soja irrigada, com produtividade média superior a $3.700 \mathrm{~kg} \mathrm{ha}^{-1}$ ); foi indicado, portanto, que nessas áreas a FBN pode não ser suficiente para suprir todo o $\mathrm{N}$ requerido pela cultura, o que justificaria o uso da adubação nitrogenada suplementar. Essa abordagem, aliada ao fato de que os custos dos adubos nitrogenados não são tão elevados nos países desenvolvidos, tem resultado em decréscimos na contribuição da FBN em países como EUA e Austrália (van Kessel \& Hartley, 2000) e não deve ser reproduzida em países como o Brasil.

Considerando-se todos os benefícios advindos das pesquisas brasileiras em $\mathrm{FBN}$, e que o potencial genético de rendimento da soja é de $8.000 \mathrm{~kg} \mathrm{ha}^{-1}$ (Specht et al., 1999), as abordagens de pesquisa devem priorizar a realização de estudos que permitam o aprimoramento contínuo desse processo. Assim, deve-se garantir que as novas cultivares de soja estabeleçam simbioses altamente eficazes no processo de FBN (Nicolás et al., 2006), inclusive no caso de materiais transgênicos.

Em relação às estirpes, o bem sucedido programa de seleção deve continuar, mas acelerado pelo uso de marcadores moleculares (Barcellos et al., 2007). Estudos de ecologia dos rizóbios também devem ser complementados, uma vez que taxas elevadas de recombinação gênica e de transferência horizontal de genes, entre estirpes inoculantes e rizóbios nativos, foram observadas em solos do Cerrado (Barcellos et al., 2007; Batista et al., 2007), e podem afetar, no futuro, as respostas à inoculação.

Énecessáriotambém darcontinuidadeaodesenvolvimento e à validação de novos inoculantes e tecnologias de inoculação, dos quais se podem citar como exemplos a inoculação no sulco, para a compatibilização com o tratamento de sementes com fungicidas e o enriquecimento das sementes em molibdênio (Campo et al., 2002).

Os resultados deste trabalho ressaltam a importância do manejo adequado do $\mathrm{N}$ em soja, para que se evite não apenas prejuízos para a fixação biológica do $\mathrm{N}_{2}$, mas também o uso desnecessário de fertilizantes nitrogenados na cultura da soja.

\section{Conclusões}

1. A utilização de fertilizantes nitrogenados em suplementação tardia para a soja, independentemente do sistema de manejo do solo, não apresenta vantagem econômica, em relação à inoculação de bradirrizóbio, em latossolos do Cerrado.

2. A nodulação da soja é prejudicada pela aplicação de $200 \mathrm{~kg} \mathrm{ha}^{-1}$ de nitrogênio e é maior em plantio direto do que em plantio convencional.

\section{Agradecimentos}

Ao Conselho Nacional de Desenvolvimento Científico e Tecnológico, pela concessão de bolsas e financiamento; ao técnico agrícola Osmar Teago de Oliveira e aos funcionários do laboratório de Microbiologia do Solo da Embrapa Cerrados: Maria das Dores Silva, Edvaldo Oliveira Neves e Clodoaldo Alves de Sousa, pela valiosa contribuição na condução dos trabalhos; ao Instituto do Milênio, pelo apoio às pesquisas.

\section{Referências}

BARCELLOS, F.G.; MENNA, P.; BATISTA, J.S.S.; HUNGRIA, M. Evidence of horizontal transfer of symbiotic genes from a Bradyrhizobium japonicum inoculant strain to indigenous diazotrophs Sinorhizobium (Ensifer) fredii and Bradyrhizobium elkanii in a Brazilian savannah soil. Applied and Environmental Microbiology, v.73, p.2635-2643, 2007. 
BATISTA, J.S.S.; HUNGRIA, M.; BARCELLOS, F.G.; FERREIRA M.C.; MENDES, I.C. Variability in Bradyrhizobium japonicum and $B$. elkanii seven years after introduction of both the exotic microsymbiont and the soybean host in a Cerrados soil. Microbial Ecology, v.53, p.270-284, 2007.

BODDEY, R.M.; URQUIAGA, S.; PERES, J.R.; SUHET, A.R.; NEVES, M.C.P. Quantification of the contribution of $\mathrm{N}_{2}$ fixation to field-grown legumes: a strategy for the practical application of the ${ }^{15} \mathrm{~N}$ isotope dilution technique. Soil Biology and Biochemistry, v.22, p.649-655, 1990.

BOTTOMLEY, P.J.; MYROLD, D.D. Biological N inputs. In: PAUL, E.A. (Ed.). Soil microbiology, ecology and biochemistry. $3^{\text {rd }}$ edition. Oxford: Academic Press, 2007. p.365-388.

CAMPO, R.J.; HUNGRIA, M.; MIURA, L.M.; MORAES, J.Z.; SIBALDELLI, R.N.R.; MESQUITA, C.M. Avaliação de estirpes de Bradyrhizobium, inoculantes microbianos e métodos de inoculação em diferentes regiões do Brasil. In: HOFFMANN-CAMPO, C.B.; SARAIVA, O.F. (Org.). Resultados de pesquisa da Embrapa Soja: 2001: microbiologia dos solos. Londrina: Embrapa Soja, 2002. p.3035. (Embrapa Soja. Documentos 197).

FERREIRA, M.C.; ANDRADE, D.S.; CHUEIRE, L.M.O.; TAKEMURA, S.M.; HUNGRIA, M. Tillage method and crop rotation on the population sizes and diversity of bradryhizobia nodulating soybean. Soil Biology and Biochemistry, v.32, p.627-637, 2000.

GAN, Y.; STULEN, I.; POSTHUMUS, F.; VAN KEULEN, H.; KUIPER, P.J.C. Effects of $\mathrm{N}$ management on growth, $\mathrm{N}_{2}$ fixation and yield of soybean. Nutrient Cycling in Agroecosystems, v.62, p.163-174, 2002.

GAN, Y.; STULEN, I.; VAN KEULEN, H.; KUIPER, P.J.C. Effect of $\mathrm{N}$ fertilizer top-dressing at various reproductive stages on growth, $\mathrm{N}_{2}$ fixation and yield of three soybean (Glycine $\max$ (L.) Merr.) genotypes. Field Crops Research, v.80, p.147-155, 2003.

HUNGRIA, M. Características biológicas em solos manejados sob plantio direto. In: REUNIÓN DE LARED LATINOAMERICANADE AGRICULTURA CONSERVACIONISTA, 5., 1999, Florianópolis. Anais. Florianópolis: Epagri, 2000. (CD-ROM).

HUNGRIA, M.; CAMPO, R.J.; MENDES, I.C.; GRAHAM, P.H. Contribution of biological nitrogen fixation to the $\mathrm{N}$ nutrition of grain crops in the tropics: the success of soybean (Glycine max (L.) Merr.) in South America. In: SINGH, R.P.; SHANKAR, N.; JAIWAL, P.K. (Ed.). Nitrogen nutrition in plant productivity. Houston: Studium Press, 2006a. p.43-93.

HUNGRIA, M.; FRANCHINI, J.C.; CAMPO, R.J.; CRISPINO, C.C.; MORAES, J.Z.; SIBALDELLI, R.N.R.; MENDES, I.C.; ARIHARA, J. Nitrogen nutrition of soybean in Brazil: contributions of biological $\mathrm{N}_{2}$ fixation and of $\mathrm{N}$ fertilizer to grain yield. Canadian Journal of Plant Science, v.86, p.927-939, 2006b.
HUNGRIA, M.; FRANCHINI, J.C.; CAMPO, R.J.; GRAHAM, P.H. The importance of nitrogen fixation to soybean cropping in South America. In: WERNER, W.; NEWTON, W.E. (Ed.). Nitrogen fixation in agriculture, forestry, ecology and the environment. Dordrecht: Springer, 2005. p.25-42.

HUNGRIA, M.; VARGAS, M.A.T.; CAMPO, R.J.; GALERANI, P.R. Adubação nitrogenada na soja? Londrina: Embrapa-CNPSo, 1997. 4p. (Embrapa-CNPSo. Comunicado Técnico, 57).

KOUTROUBRAS, S.D.; PAPAKOSTA, D.K.; GAGIANAS, A.A. The importance of early dry matter and nitrogen accumulation in soybean yield. European Journal of Agronomy, v.9, p.1-10, 1998.

LAMOND, R.E.; WESLEY, T.L. Adubação nitrogenada no momento certo para soja de alta produtividade. Informações Agronômicas, v.95, p.6-7, 2001.

MENDES, I.C.; HUNGRIA, M.; VARGAS, M.A.T. Soybean response to starter nitrogen and Bradyrhizobium inoculation on a Cerrado Oxisol under no-tillage and conventional tillage systems. Revista Brasileira de Ciência do Solo, v.27, p.81-87, 2003.

NICOLÁS, M.F.; HUNGRIA, M.; ARIAS, C.A.A. Identification of quantitative trait loci controlling nodulation and shoot mass in progenies from two Brazilian soybean cultivars. Field Crops Research, v.95, p.355-366, 2006.

PAPACOSTA, D.K.; VERESOGLOU, D.S. Responses of soybean cultivars to inoculation and nitrogen application in Greece in fields free of Bradyrhizobium japonicum. Journal of Agronomy and Crop Science, v.163, p.275-283, 1989.

PEREIRA, A.A.; HUNGRIA, M.; FRANCHINI, J.C.; KASCHUK, G.; CHUEIRE, L.M.O.; CAMPO, R.J.; TORRES, E. Variações qualitativas e quantitativas na microbiota do solo e na fixação biológica do nitrogênio sob diferentes manejos com soja. Revista Brasileira de Ciência do Solo, v.31, p.1397-1412, 2007.

PERES, J.R.R.; MENDES, I.C.; SUHET, A.R.; VARGAS, M.A.T. Eficiência e competitividade de estirpes de rizóbio para a soja em solos de Cerrados. Revista Brasileira de Ciência do Solo, v.17, p.357-363, 1993.

PERES, J.R.R.; VIDOR, C. Seleção de estirpes de Rhizobium japonicum e competitividade por sítios de infecção nodular em cultivares de soja. Agronomia Sulriograndense, v.16, p.205-219, 1980.

SAS INSTITUTE. SAS/STAT: user's guide: version 8. Cary: SAS Institute, 2000.

SOUSA, D.M.G. de; LOBATO, E. Calagem e adubação para culturas anuais e semiperenes. In: SOUSA, D.M.G. de; LOBATO, E. (Ed.). Cerrado: correção do solo e adubação. Planaltina: Embrapa Cerrados, 2002. p.283-316.

SPECHT, J.E.; HUME, D.J.; KUMUDINI, S.V. Soybean yield potential: a genetic and physiological perspective. Crop Science, v.39, p.1560-1570, 1999.

Pesq. agropec. bras., Brasília, v.43, n.8, p.1053-1060, ago. 2008 
THIES, J.E.; SINGLETON, P.W.; BOHLOOL, B.B. Modeling symbiotic performance of introduced rhizobia in the field by use of indices of indigenous population size and nitrogen status of the soil. Applied and Environmental Microbiology, v.57, p.29-37, 1991.

THIES, J.E.; WOOMER, P.L.; SINGLETON, P.W. Enrichment of Bradyrhizobium spp. populations in soil due to cropping of the homologous host plant. Soil Biology and Biochemistry, v.27, p.633-636, 1995.

VAN KESSEL, C.; HARTLEY, C. Agricultural management of grain legumes: has it led to an increase in nitrogen fixation? Field Crops Research, v.65, p.165-181, 2000.

VARGAS, M.A.T.; PERES, J.R.R.; SUHET, A.R. Adubação nitrogenada, inoculação e épocas de calagem para a soja em um solo sob Cerrado. Pesquisa Agropecuária Brasileira, v.17, p.1127-1132, 1982.

VARGAS, M.A.T.; SUHET, A.R. Efeitos de tipos e níveis de inoculantes na soja cultivada em um solo de Cerrado. Pesquisa Agropecuária Brasileira, v.15, p.343-347, 1980.

WESLEY, T.L.; LAMOND, R.E.; MARTIN, V.L.; DUNCAN, S.R. Effects of late-season nitrogen fertilizer on irrigated soybean yield and composition. Journal of Production Agriculture, v.11, p.331-336, 1998.

WOOD, C.W.; TORBERT, H.A.; WEAVER, D.B. Nitrogen fertilizer effects on soybean growth, yield, and seed composition. Journal of Production Agriculture, v.6, p.354-360, 1993.

$\overline{\text { Recebido em } 11 \text { de abril de } 2008 \text { e aprovado em } 15 \text { de julho de } 2008}$ 